\title{
An Empirical Comparison of Different Two-Factor Models in the Context of Portfolio Optimisation
}

Jamal Agouram ${ }^{\text {*1 }}$, Mouncif Harabida ${ }^{2}$, Bouchra Radi ${ }^{2}$, Ghizlane Lakhnati ${ }^{3}$

${ }^{1}$ Laboratory of Studies and Applied Researches in Economic Sciences (LERASE), Faculty of Law, Economics and Social Sciences, Ibn Zohr University, Agadir, 80000, Morocco

${ }^{2}$ Entrepreneurship, Finance and Audit Research Laboratory (LAREFA), National School of Business and Management (ENCG), Ibn Zohr University, Agadir, 80000, Morocco

${ }^{3}$ Laboratory of industrial engineering and informatics (LGII), National School of Applied Sciences (ENSA), Ibn Zohr University, Agadir, 80000, Morocco

\section{A R T I C LE INFO}

Article history:

Received: 04 September, 2020

Accepted: 21 September, 2020

Online: 05 October, 2020

\section{Keywords:}

COVID-19

Gini coefficient

Lower Partial Moments

Mean Absolute Deviation

(MAD)

Mean-Gini $(M G)$

Mean-Variance (MV)

\begin{abstract}
A B S T R A C T
The crisis linked to the COVID-19 and the uncertainty it generates in the unprecedented health, societal, economic and financial fields have had a strong impact on the stock markets. Indeed, in such a climate of very high uncertainty, it is to be expected that the excessive stock market price movements will continue, with both declines and technical rebounds, and that the resulting volatility will remain particularly high. In order to cope with this crisis, investors and portfolio managers must mobilize all portfolio selection strategies. In particular, portfolio management and construction are based on the concepts of return and risk. This couple has been at the center of all the concerns of managers and investors in portfolio optimization issues since the introduction of the mean-variance model by Markowitz. However, many studies have proposed different measures of risk to overcome the drawbacks of variance. The objective of this paper is to present and compare the portfolio compositions and performance of four different portfolio optimization models using different risk measures, including variance, Mean Absolute Deviation, Gini coefficient and Lower Partial Moments (LPM). The results of this study show that the Mean-Lower Partial Moments (MLPM) model outperforms other models. The Mean-Lower Partial Moments (MLPM) model is suitable for investors during the crisis period (COVID-19) in the Moroccan financial market.
\end{abstract}

\section{Introduction}

During a financial crisis, it is crucial for investors and portfolio managers to implement the best portfolio selection model that takes into account investors' risk and return preferences. Several studies have evaluated and compared different portfolio management strategies according to their return and risk characteristics. The portfolios are made up of financial assets such as shares, bonds, credits, and options. A fundamental question in the management of asset portfolios is the choice of valid investment objectives. In the context of risk, individuals make decisions based on two fundamental parameters (return and risk).

Return ${ }^{1}$ and risk $k^{2}$ are two associated concepts in finance. Indeed, in the case of an investment in a risky financial asset, an investor will demand a higher return or a lower risk and investment decisions boil down to finding an optimal compromise between return and risk. So an investor who wishes to improve the return on his portfolio must accept to take more risk.

The notion of risk derives from changes in the prices of financial assets and their negative impact on the total financial value of the portfolio.

Therefore, the risk is a very important component in portfolio management. While the return is easy to assess, risk has not received consensus on what constitutes its fair measurement. Risk can be considered as variance (e.g., Markowitz [1], [2] [2], [3]; Tobin [4]; Sharpe [5]; Lintner [6], [7]; Mossin [8]; semi-variance Markowitz [3]; partial lower moments (e.g. Bawa [9], Bawa and Lindenberg [10], Fishburn [11] and Harlow and Rao [12], the so-called Value at

\footnotetext{
*Corresponding Author: Jamal Agouram, +212661653888 \& jamal.agouram@edu.uiz.ac.ma

${ }^{1}$ Return is an indicator that measures the relative appreciation or depreciation of the value of a financial asset or portfolio of assets over a given period.

${ }^{2}$ The notion of risk derives from changes in the prices of financial assets and their negative impact on the total financial value of the portfolio.
} 
Risk Morgan [13], Jorion [14], Grebeck [15].

So the risk and return couple will be very central terms in our analysis and it is essential that we understand the meaning of each term and how portfolios with different structures can be compared. To this end an overview of performance measures will be used to compare the performance of portfolios, providing investors with useful information on the capacity of managers and providing tools to assess the risk taken by the manager based on the different twofactor models.

In what follows, we will first briefly review the literature on two-factor models. The second section is devoted to the application of these models to real data from the Moroccan financial market. Portfolio performance measures will be used in the third section to compare the models.

\section{Literature review}

The advent of the Covid-19 pandemic, which includes both the Severe Acute Respiratory Syndrome (SARS) virus and the Middle East Syndrome (MOS), has led to major disruptions in world economies and particularly in financial markets. In fact, the financial markets reacted negatively to the growth of the cases confirmed by Covid-19 by posting abnormal negative returns on listed equities, reflecting investors' aversion to the pandemic. This crisis, like previous crises in the world's financial markets, has placed risk control at the center of the concerns of investors and portfolio management companies. Moreover, each of these crises is an opportunity to advance the risk measurement and management tools proposed by theorists and researchers in this field. In a risky environment, investors make decisions based on their selection criteria. Consequently, decision theory has been used as a basis for investment choice theory and portfolio management.

Indeed, many economists and financial theorists have used the fundamental contributions of decision theory since the middle of the 20th century to evaluate investment opportunities. The theory that has dominated risk studies since its emergence in 1944 is the theory of expected utility. The latter has become widely accepted in all areas of economic theory incorporating the risk factor. Parallel to this, Harry Markowitz [1] proposed his famous Mean-Variance model and gave the starting signal for modern portfolio choice theory. Indeed, the use of utility functions is often complex and does not lead to analytical solutions. This is why Markowitz simplified the problem of choice in uncertainty in order to solve it in a simple and explicit way. His idea was to measure the risk affecting a wealth by its variance.

The investor is then presumed to make decisions based on only two parameters: the first reflects the return on the investment measured by the expected return desired and the second reflects the risk measured by the variance. Markowitz asserts the strength of the relationship between return and risk because he has shown that, under certain conditions, investors can manage to balance their hopes of obtaining portfolios that have both the best possible return and a minimum of risk.

This approach leads to the theory of efficient portfolios, which suggests combining appropriate proportions of assets in a portfolio. A little later, Treynor [16], [17], Sharpe [5], Lintner [6], and Mossin [8] developed the Financial Asset Equilibrium Model (CAPM) which, under certain assumptions, leads to an equilibrium return for any stock. Later, Ross [18] developed an alternative to CAPM called Price Arbitration Theory (PAT) based on multifactorial models. The Markowitz, CAPM, and APT models form the core of classical portfolio theory.

The latter has revolutionized the way portfolio management is conceived and its contributions have become absolutely essential even today. However, the application of the Mean-Variance (MV) model in portfolio selection is questionable because this model is only valid if returns are normally distributed or if the investors have quadratic preferences. However, several researches have shown that returns on financial assets are not normally distributed. Similarly, Ballestero [19], Bond and Satchell [20], [21], Estrada [22], and Unser [23] have pointed out that variance is a dubious measure of risk because it treats above-average and below-average returns in the same way, whereas investors associate risk with returns below the target rate of return.

The restrictive nature of variance as a measure of risk in the Markowitz model has motivated a large number of studies to seek more appropriate risk measures. Markowitz [3], Fishburn [11], and Bawa and Lindenberg [10] have proposed the use of Lower Partial Moments.

To remedy the imperfections of the Mean-Variance approach, Shalit and Yitzhaki [24] introduced the Mean-Gini model in portfolio management as an alternative to the mean-variance model. The Mean-Gini model (MG) uses the Gini coefficient as the risk parameter rather than variance. Thus, the concept proposed by Shalit and Yitzhaki [24] is similar to Markowitz's [1], because it is based on two parameters. In addition, the Mean-Gini strategy can circumvent assumptions about the normality of the distribution of returns, and of the quadratic function of the utility function. Yitzhaki [25] showed also that the Gini coefficient satisfies the stochastic dominance of the second degree, which makes the Mean-Gini model compatible with the theory of expectation of utility.

Later, Shalit and Yitzhak [24] [26] presented the Generalised Mean-Gini (GMM) as a model that provides a measure to embody the preferences of different investors regarding their degree of risk aversion. As a result, this model can better reflect the perceived risk of an individual investor, as highlighted in the recent study by Cardin et al [27]. For these reasons, this theory is seen as an alternative to the traditional approach that has been dominant in financial theory for more than half a century. While Konno and Yamazaki [28], in contrast to Markowitz's quadratic model, proposed the first linear model by replacing the variance with the mean absolute deviation (MAD) as a measure of risk. 


\subsection{The Mean-Variance of Markowitz}

The Mean-Variance model offers the investor a set of efficient portfolios, i.e. those with the lowest risk for a possible overall return ${ }^{3}$ , and vice versa. This method uses only the concepts of mean for the expected return and variance $\Theta^{4}$ for the uncertainty associated with this return, hence the name Mean-Variance 5 associated with Markowitz analysis.

The variance of a portfolio combination of securities is equal to the weighted average covariance ${ }^{6}$ of the returns on its individual securities:

$$
\operatorname{Var}\left(r_{p}\right)=\sigma_{p}^{2}=\sum_{i=1}^{N} \sum_{j=1}^{N} x_{i} x_{j} \operatorname{Cov}\left(r_{i}, r_{j}\right)
$$

Markowitz's[2] model may be written as the following non-linear quadratic programming model:

$$
\begin{gathered}
\min \sum_{i=1}^{N} \sum_{j=1}^{N} x_{i} x_{j} \operatorname{Cov}\left(r_{i}, r_{j}\right) \\
\text { s.t }: \sum_{i=1}^{N} x_{j} r_{j} \geq w_{0} \\
\sum_{i=1}^{N} x_{j}=1 \\
0 \leq x_{j} \leq u_{j}, j \in N
\end{gathered}
$$

The first constraint simply says that the expected return on the portfolio should equal the target return determined by the portfolio manager $\left(w_{0}\right)$. The second constraint says that the weights of the securities invested in the portfolio must sum to one. The last constraint stipulates that asset weights must be positive, i.e. short sales are not allowed.

Since its appearance, the Markowitz model has taken a very important place in the evolution of modern finance and has achieved great success with its contribution to portfolio management. But with recent adjustments, this model has found several limitations raised by several practitioners of financial theory. As with any model, the limitations are generally focused around these assumption: ${ }^{7}$ as well as on the estimation of these parameters.

\subsection{The Mean-Lower Partial Moment Model}

This concept was introduced by Bawa [9] and Fishburn [11] and Nawrocki [30]-[32] to define measures of downside risk in general. Since the variance takes into account all negative as well as positive deviations, lower partial moments only take into account negative deviations. Semi-variance is a special case of a class of asymmetric measures proposed by Markowitz [3] in the case where the investor is indifferent between two or more securities after having calculated the variance, i.e. the variance is sometimes insufficient to make the right decision. Semi-variance is a type of measure known as a measure of downside risk. This type of measure focuses primarily on losses. Unlike variance, no assumptions are made about the statistical distribution of asset returns. Thus, the lower partial moments represent, in a way, the standard deviation of returns below a target return. They do not penalize returns above a target return and differentiate between risk, returns below a minimum return, uncertainty and variability of returns. Bawa and Lindenberg [10], Lee and Rao [33], and Harlow and Rao [12] have developed lower partial mean-moment models (LPMM), and have shown their advantages over the Mean-Variance (MV) model. Despite these efforts, few studies have empirically examined these advantages.

Bawa (1975) developed the concept of downside risk by lower partial moments (MPM) of order $n$ with a target rate of return $t^{8}$ defined in continuous time by:

$$
\operatorname{LPM}_{\alpha}\left(\tau, R_{i}\right)^{\alpha}=\int_{-\infty}^{\tau}(\tau, R)^{\alpha} d F(R)
$$

Where $R, F, \tau$, and $n$ denote respectively the rate of return of a security or portfolio, the probability distribution of that return, the target rate of return, and the degree of the moment.

Under these conditions, the portfolio choice problem according to the Mean-Lower Partial Moment Model criterion consists in solving the following optimization problem:

$$
\begin{gathered}
\min \sum_{t=1}^{\tau} p_{t} z_{t}^{2} \\
z_{t} \geq \sum\left(r_{j t}-r_{j}\right) x_{j}, t=1,2, \ldots, T \\
z_{t} \geq 0, t=1,2, \ldots, T
\end{gathered}
$$

${ }^{3}$ In practice, the statistical parameters are often estimated at Based on time series (such as historical data from the financial markets), and after that they are somehow adjusted. Given any set of risky assets and a set of weights that describe how the portfolio investment is split, the general formula of expected return for $\mathrm{n}$ assets is:

$$
E\left(r_{p}\right)=\sum_{j=1}^{N} x_{j} r_{j}
$$

where: $N$ the number of securities; $x_{j}$ is the proportion of the funds invested in security $j ; r_{j}$ are the return on ith security $j$ and portfolio $p$; and $E()$ is the expectation of the variable in the parentheses.

${ }^{4}$ As long as the assets are supposed to be characterized by distributions symmetrical, the variance or standard deviation are good measures because any normal distribution is fully described by its mean value and its variance (or standard deviation) (see, for example, Artzner et al [29]). Variance is not a good measure of risk if we are dealing with financial assets that are characterized by unsymmetric gains.

${ }^{5}$ Although the mean-variance approach proposed by Markowitz has been used extensively in practice, it has several limitations (computational load, the non-linear (quadratic) nature of the risk measure, the perception of non-symmetrical risk, the normal distribution of returns, and many others).

${ }^{6} \mathrm{High}$ covariance indicates that an increase in one stock's return is likely to correspond to an increase in the other. A low covariance means the return rates are relatively independent and a negative covariance means that an increase in one stock's return is likely to correspond to a decrease in the other.

${ }^{7}$ As with any model, Markowitz-style portfolio selection is based on several assumptions about individual behaviour and the context of uncertainty.

${ }^{8}$ In the case where $t$ is the mean of the return distribution, we find the traditional semi-variance as introduced by Markowitz. 


$$
\begin{gathered}
\sum_{i=1}^{N} x_{j}=1 \\
0 \leq x_{j} \leq u_{j}, j \in N
\end{gathered}
$$

In order to test the Mean-Lower Partial Moment Model, we chose to place ourselves in a semi-variance context.

\subsection{The Mean Absolute Deviation}

The alternative presented by Konno and Yamazaki [28] suggests that Markowitz-type portfolio optimisation could be replaced or even improved by a model using the mean absolute deviation (MAD ${ }^{9}$ ) as a measure of risk to overcome the weaknesses of Markowitz's [2] non-linear model. The DSM results in a linear programming model, which proves to be equivalent to the Markowitz model and easier to compute. The DSM linear programming model, proposed by Konno \& Yamazaki [28], can be posed as follows:

$$
\min \sum_{t \in T} p_{t} y_{t}
$$

s.t: "Markowitz" constraints (2)-(3)

$$
\begin{gathered}
y_{t}+\sum_{j \in N}\left(r_{j t}-r_{j}\right) x_{j} \geq 0, t=1,2, \ldots, T \\
y_{t}-\sum_{j \in N}\left(r_{j t}-r_{j}\right) x_{j} \geq 0, t=1,2, \ldots, T \\
0 \leq x_{j} \leq u_{j}, j \in N
\end{gathered}
$$

\subsection{The Mean-Gini (MG) model}

The Mean-Gini (MG) model was originally developed by Yitzhaki [25]. Then, it was applied in finance by Shalit and Yitzhaki [24] as an alternative model to the Mean-Variance model to assess risk and construct optimal portfolios that are consistent with the theory of utility expectation and stochastic dominance. The Mean-Gini (MG) model shows strong results when the mean-variance model is doomed to failure, particularly when assets are not normally distributed.

The Mean-Gini (MG) approach in finance is used by Bey and Howe [34] in portfolio analysis, Okunev [35] to evaluate the performance of mutual funds, Shalit and Yitzhaki [24] and agouram \& lakhnati [36] [37] [38] to obtain optimal portfolio selection, Cheung et al. [39] to examine the effectiveness of hedging options and futures contracts, and Berkhouch et al. [40] introduced and applied the Tail Extended Gini functional and the Extended Gini Shortfall on daily returns for the MASI index.

Recall that the Gini coefficient is equal to:

$$
\Gamma_{p}=2 \operatorname{cov}\left(R_{p}, F\left(R_{p}\right)\right)
$$

where $R_{p}$ is the portfolio return and $F\left(R_{p}\right)$ is is the cumulative distribution function. Thus, the mathematical optimization problem is presented as follows:

$$
\begin{gathered}
\min \Gamma_{p}=2 \operatorname{cov}\left(R_{p}, F\left(R_{p}\right)\right)=2 \sum_{i=1}^{N} x_{i} \operatorname{cov}\left(R_{i}, F\left(R_{p}\right)\right) \\
\text { s.t }: \sum_{i=1}^{N} x_{j} r_{j} \geq w_{0} \\
\quad \sum_{i=1}^{N} x_{j}=1 \\
0 \leq x_{j} \leq u_{j}, j \in N
\end{gathered}
$$

where $\Gamma_{p}$ is the Gini coefficient of the portfolio, $x_{j}$ is the weight of asset $j, r_{j}$ is the expected return on asset $\mathrm{j}$ per period, $w_{0}$ is the minimum rate of return required by the investor.

\section{Data and Methodology}

Our study focuses on a sample of securities of the MADEX Index for which we collected daily prices over the period from September 7, 2015 to August 28, 2020. The MADEX Index groups the values of 45 securities according to their capitalization and volumes traded. The index is therefore representative of the most capitalized and liquid securities listed on the Casablanca Stock Exchange.

The data will be used as follows:

- First of all, we will use the first 1113 daily returns, corresponding to the period from September 7th 2015 to February 28th 2020 (the date of appearance of the first positive case in Covid-19), for the composition of the four portfolios.

- Next, we will estimate the performance measures of the four portfolios in order to compare them. To calculate the performance of these portfolios, we use the following three performance measures : Sharpe Ratio, Treynor Ratio, Jensen Alpha. To be more precise, we will use the risk-adjusted Sharpe ratio of each model. We will use the following formulas:

$$
S_{P}=\frac{E\left(R_{P}\right)-r_{f}}{R_{\text {measure }}}
$$

Where $S_{P}$ is the Sharpe ratio, $E\left(R_{P}\right)$ is the portfolio return, $r_{f}$ is the return on risk-free assets and $R_{\text {measure }}$ is the risk measure of each model.

$$
T_{P}=\frac{E\left(R_{P}\right)-r_{f}}{\beta_{P}}
$$

${ }^{9}$ The mean absolute deviation is defined as the mean of the absolute values of the differences between the observations and their mean :

$$
M A D(R)=\frac{1}{n} \sum_{i=1}^{n}\left|R_{i}-\bar{R}\right|
$$

Where $n$ is the number of observed values, $\bar{R}$ is the mean of the observed values and $R_{i}$ are the individual values.

Absolute mean deviation is a more robust scale estimator relative to standard deviation and more resistant to outliers in a data set. For a larger mean absolute deviation, the risk is high. 
where $T_{P}$ is the Treynor Ratio, $E\left(R_{P}\right)$ is the portfolio return, $r_{f}$ is the return on risk-free assets and $\beta_{P}$ is is the beta of the portfolio. where $S_{P}$ is the Jensen Alpha, $E\left(R_{P}\right)$ is the portfolio return, $r_{f}$ is the return on risk-free assets and $\beta_{P}$ is is the beta of the portfolio.

$$
\alpha=E\left(R_{P}\right)-\left(r_{f}+\beta_{P}\left(E\left(R_{m}\right)-r_{f}\right)\right.
$$

Table 1: Summary of datasets used

\begin{tabular}{|c|c|c|c|c|c|c|c|c|}
\hline Stocks & Mean & $\begin{array}{c}\text { Standard } \\
\text { Deviation }\end{array}$ & Max & Min & Skewnes & Kurtusis & $\begin{array}{l}\text { Jarque-Bera } \\
\text { Test Statistic }\end{array}$ & $\begin{array}{c}\text { P-Value } \\
\text { Jarque-Bera }\end{array}$ \\
\hline $\mathrm{ADH}$ & -0.0008 & 0.0230 & 0.0998 & -0.0999 & -0.0723 & 5.2333 & 1268.78 & 0.0000 \\
\hline ADI & 0.0004 & 0.0333 & 0.2075 & -0.1087 & 0.4387 & 3.0088 & 454.71 & 0.0000 \\
\hline ALM & 0.0014 & 0.0308 & 0.0995 & -0.1172 & -0.1525 & 0.4731 & 14.67 & 0.0007 \\
\hline ATH & 0.0002 & 0.0224 & 0.0999 & -0.0999 & -0.0115 & 2.0090 & 186.86 & 0.0000 \\
\hline ALT & 0.0004 & 0.0197 & 0.0998 & -0.0777 & 0.2459 & 2.7947 & 372.75 & 0.0000 \\
\hline ATW & 0.0004 & 0.0099 & 0.0425 & -0.0489 & 0.2240 & 2.7070 & 348.50 & 0.0000 \\
\hline $\mathrm{BCI}$ & 0.0002 & 0.02892 & 0.0997 & -0.2014 & -0.2243 & 2.7009 & 347.00 & 0.0000 \\
\hline BCP & 0.0002 & 0.0111 & 0.0685 & -0.0925 & -0.0133 & 8.1582 & 3081.04 & 0.0000 \\
\hline BOA & -0.0001 & 0.0130 & 0.0997 & -0.0801 & 0.8456 & 8.2679 & 3296.83 & 0.0000 \\
\hline $\mathrm{CIH}$ & 0.0001 & 0.0189 & 0.0820 & -0.0754 & 0.2327 & 2.4187 & 280.83 & 0.0000 \\
\hline CMA & 0.0012 & 0.0226 & 0.0994 & -0.0993 & 0.0608 & 1.6813 & 131.53 & 0.0000 \\
\hline CMT & 0.0004 & 0.0217 & 0.1000 & -0.1146 & -0.2687 & 4.7220 & 1045.55 & 0.0000 \\
\hline $\mathrm{COL}$ & 0.0007 & 0.0290 & 0.2001 & -0.2050 & 0.0516 & 4.8696 & 1098.20 & 0.0000 \\
\hline CRS & 0.0010 & 0.0309 & 0.1000 & -0.0997 & 0.2107 & 1.1873 & 73.47 & 0.0000 \\
\hline CTM & 0.0015 & 0.0252 & 0.2553 & -0.1522 & 1.2173 & 14.2007 & 9609.58 & 0.0000 \\
\hline DHO & 0.0005 & 0.0232 & 0.0997 & -0.0909 & 0.2774 & 2.3334 & 266.30 & 0.0000 \\
\hline DLM & -0.0009 & 0.0383 & 0.1231 & -0.2189 & -0.4775 & 2.1645 & 259.10 & 0.0000 \\
\hline DWY & 0.0007 & 0.0251 & 0.1448 & -0.0999 & 0.4550 & 3.2230 & 519.21 & 0.0000 \\
\hline FBR & -0.0003 & 0.0403 & 0.1415 & -0.1550 & 0.0178 & 0.3493 & 5.70 & 0.0576 \\
\hline GAZ & 0.0013 & 0.0286 & 0.0998 & -0.0997 & 0.0523 & 0.7583 & 27.12 & 0.0000 \\
\hline HPS & 0.0026 & 0.0283 & 0.1000 & -0.1577 & -0.0732 & 1.6319 & 124.27 & 0.0000 \\
\hline IAM & 0.0003 & 0.0086 & 0.0582 & -0.0752 & -0.5511 & 12.7913 & 7630.40 & 0.0000 \\
\hline IBC & -0.0015 & 0.0424 & 0.1909 & -0.2186 & 0.0141 & 1.5426 & 110.18 & 0.0000 \\
\hline INV & 0.0006 & 0.0369 & 0.1238 & -0.1150 & 0.0913 & 0.4477 & 10.82 & 0.0045 \\
\hline JET & 0.0005 & 0.0288 & 0.1000 & -0.1364 & 0.1825 & 1.9568 & 183.42 & 0.0000 \\
\hline LBV & 0.0010 & 0.0257 & 0.0990 & -0.0997 & 0.0424 & 1.4843 & 102.32 & 0.0000 \\
\hline LES & 0.0007 & 0.0194 & 0.0993 & -0.0877 & 0.4733 & 2.7353 & 387.82 & 0.0000 \\
\hline LHM & 0.0004 & 0.0209 & 0.0997 & -0.0997 & -0.0274 & 2.4867 & 286.38 & 0.0000 \\
\hline LYD & 0.0007 & 0.0275 & 0.0952 & -0.0998 & 0.0352 & 0.8244 & 31.68 & 0.0000 \\
\hline M2M & 0.0015 & 0.0344 & 0.1000 & -0.1000 & 0.2485 & 0.3014 & 15.63 & 0.0004 \\
\hline MDP & 0.0001 & 0.0390 & 0.2091 & -0.3126 & 0.0467 & 4.5041 & 939.52 & 0.0000 \\
\hline MIC & 0.0016 & 0.0273 & 0.0999 & -0.0963 & 0.2107 & 1.0399 & 58.27 & 0.0000 \\
\hline MNG & 0.0002 & 0.0290 & 0.2109 & -0.0996 & 0.3517 & 4.0247 & 772.74 & 0.0000 \\
\hline NKL & 0.0002 & 0.0280 & 0.0982 & -0.0997 & -0.0110 & 1.6414 & 124.73 & 0.0000 \\
\hline RDS & -0.0009 & 0.0235 & 0.0999 & -0.0999 & 0.0537 & 2.1790 & 220.32 & 0.0000 \\
\hline RIS & 0.0000 & 0.0289 & 0.1000 & -0.0998 & 0.1481 & 1.1046 & 60.53 & 0.0000 \\
\hline S2M & 0.0005 & 0.0277 & 0.1937 & -0.1357 & 0.2211 & 3.2267 & 491.01 & 0.0000 \\
\hline SAH & 0.0005 & 0.0280 & 0.0997 & -0.0999 & 0.0060 & 1.8116 & 151.93 & 0.0000 \\
\hline SID & -0.0009 & 0.0285 & 0.1000 & -0.1005 & 0.1213 & 1.6771 & 132.92 & 0.0000 \\
\hline SLF & 0.0005 & 0.0212 & 0.0979 & -0.1264 & -0.2940 & 4.2780 & 863.19 & 0.0000 \\
\hline SMI & 0.0008 & 0.0320 & 0.0908 & -0.1334 & -0.0988 & 0.2294 & 4.24 & 0.1199 \\
\hline SNP & 0.0019 & 0.0331 & 0.1000 & -0.1000 & 0.3789 & 1.4434 & 123.02 & 0.0000 \\
\hline STR & -0.0013 & 0.0422 & 0.1000 & -0.1900 & -0.0111 & 0.6210 & 17.87 & 0.0001 \\
\hline TQM & 0.0007 & 0.0155 & 0.0758 & -0.0656 & 0.1101 & 2.0392 & 194.73 & 0.0000 \\
\hline WAA & 0.0005 & 0.0276 & 0.0989 & -0.0998 & 0.0771 & 0.8688 & 36.03 & 0.0000 \\
\hline
\end{tabular}




\section{Empirical Results and Discussion}

This study begins with an analysis of the characteristics of the 45 selected stocks that will enable us to build our portfolios according to the Mean-Variance (MV), Mean-Absolute Deviation (MAD), MeanLower Partial Moments (MLPM) and Mean-Gini (MG) strategies. Descriptive statistics are presented in Table 1. The normality test (Jarque-Bera) for each stock led us to reject the null hypothesis of the normality test at the $99 \%$ confidence level. This non-normality of returns does not seem to make the Mean-Variance test relevant (Amato et ali, 1999 [39]), we assume that in the context of our data, the Mean-Variance strategy is the least appropriate. These results indicate a property already observed in the financial data series that returns are generally not normally distributed. In addition, other properties of risky assets were found in the data series such as skewness and kurtosis. Figures 1, 2, 3 and 4 represent the daily returns of the different strategies during the crisis period from February 28, 2020 to August 28, 2020.

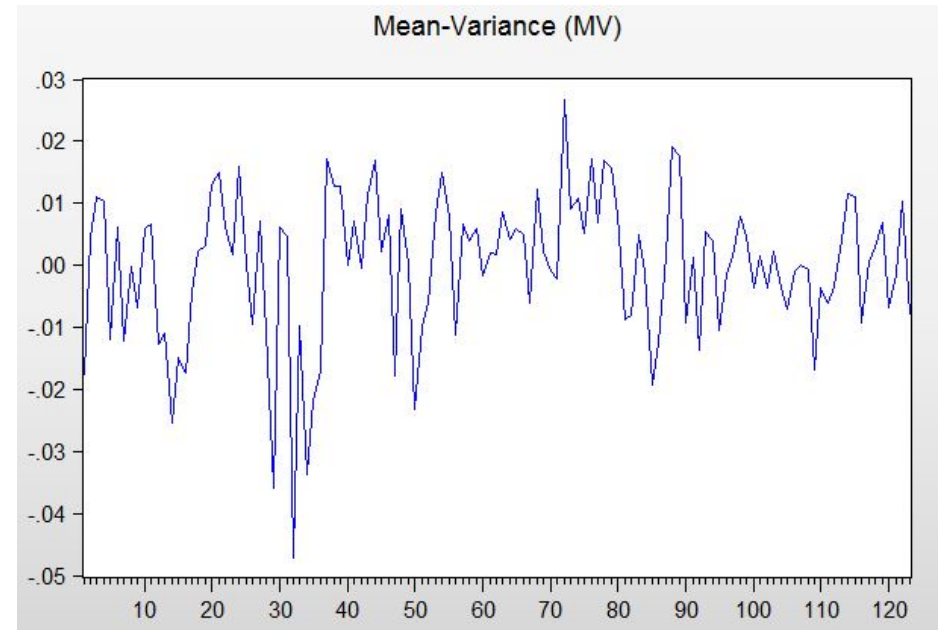

Figure 1: Graphical representation of return ( Mean-Variance (MV)).

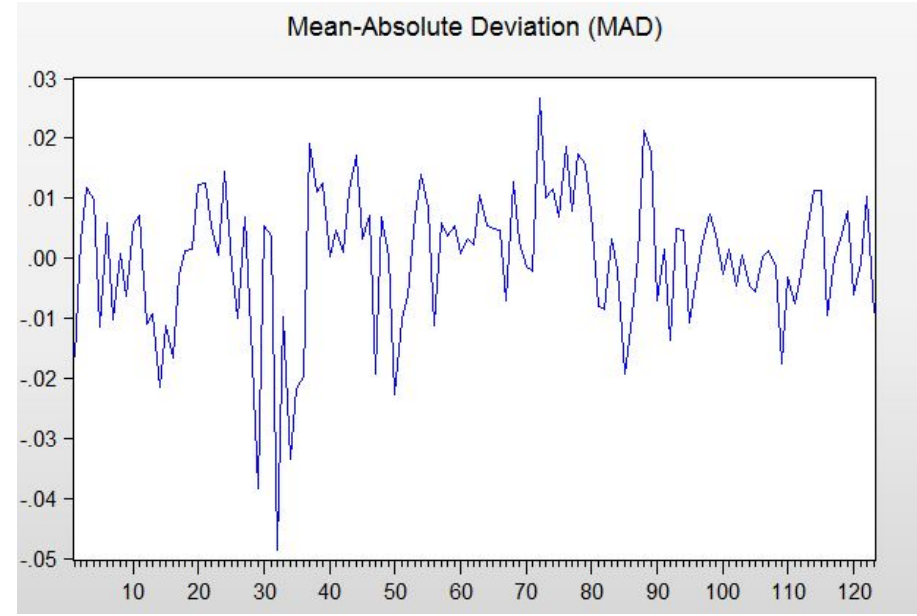

Figure 2: Graphical representation of return ( Mean-Absolute Deviation (MAD)).
Table 2: Composition of the different portfolios

\begin{tabular}{|c|c|c|c|c|}
\hline & $\begin{array}{c}\text { Mean- } \\
\text { Variance }\end{array}$ & $\begin{array}{c}\text { Mean-Abslute } \\
\text { Devaiation }\end{array}$ & $\begin{array}{c}\text { Mean- } \\
\text { Semivariance }\end{array}$ & $\begin{array}{c}\text { Mean- } \\
\text { Gini }\end{array}$ \\
\hline ALM & $7.73 \%$ & $8.19 \%$ & $3.97 \%$ & $7.83 \%$ \\
\hline CMA & $2.40 \%$ & $4.12 \%$ & $2.61 \%$ & $3.06 \%$ \\
\hline CTM & $11.40 \%$ & $12.92 \%$ & $11.14 \%$ & $11.54 \%$ \\
\hline GAZ & $3.53 \%$ & $2.70 \%$ & $4.38 \%$ & $3.77 \%$ \\
\hline HPS & $39.94 \%$ & $41.27 \%$ & $39.14 \%$ & $40.51 \%$ \\
\hline M2M & $6.60 \%$ & $5.50 \%$ & $7.33 \%$ & $6.05 \%$ \\
\hline MIC & $13.56 \%$ & $13.06 \%$ & $14.69 \%$ & $13.30 \%$ \\
\hline SNP & $14.84 \%$ & $12.25 \%$ & $16.73 \%$ & $13.94 \%$ \\
\hline
\end{tabular}

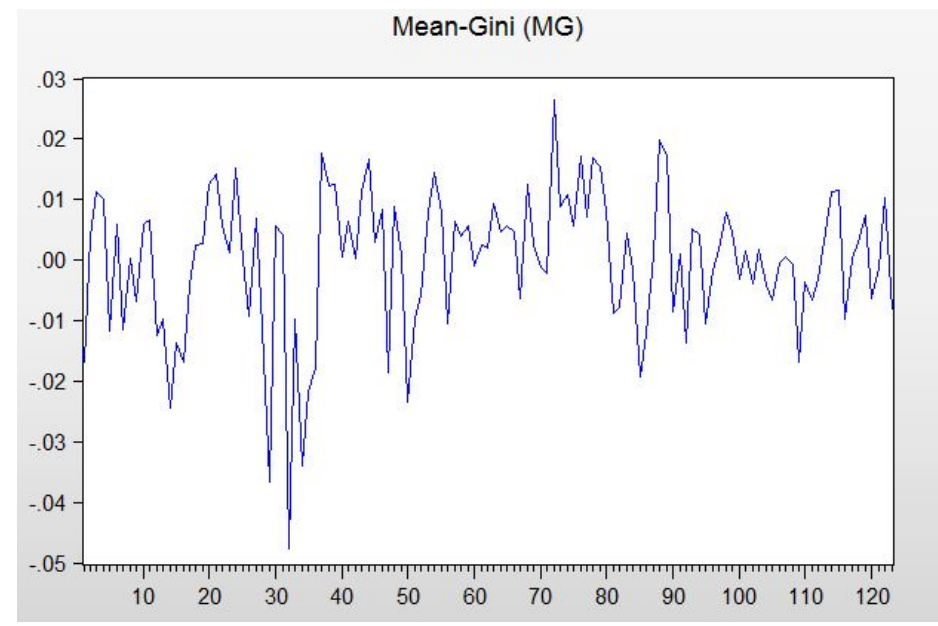

Figure 3: Graphical representation of return ( Mean-Gini (MG)).

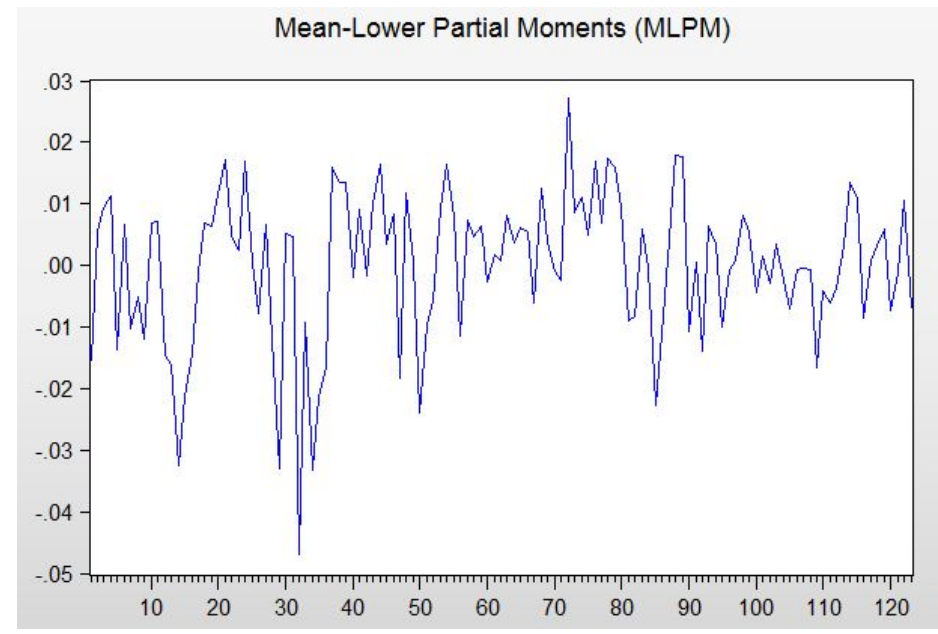

Figure 4: Graphical representation of return ( Mean-Lower Partial Moments (MLPM)).

Table 2 above gives the proportions of each share in the optimal portfolios. The results show that the compositions are different as each portfolio has its own composition of shares but with the same assets (ALM, CMA, CTM, GAS, HPC, M2M, MIC, SNP) as the objective return for the period was 0.002 while the majority of the assets have negative returns. For the Mean-Variance strategy, 


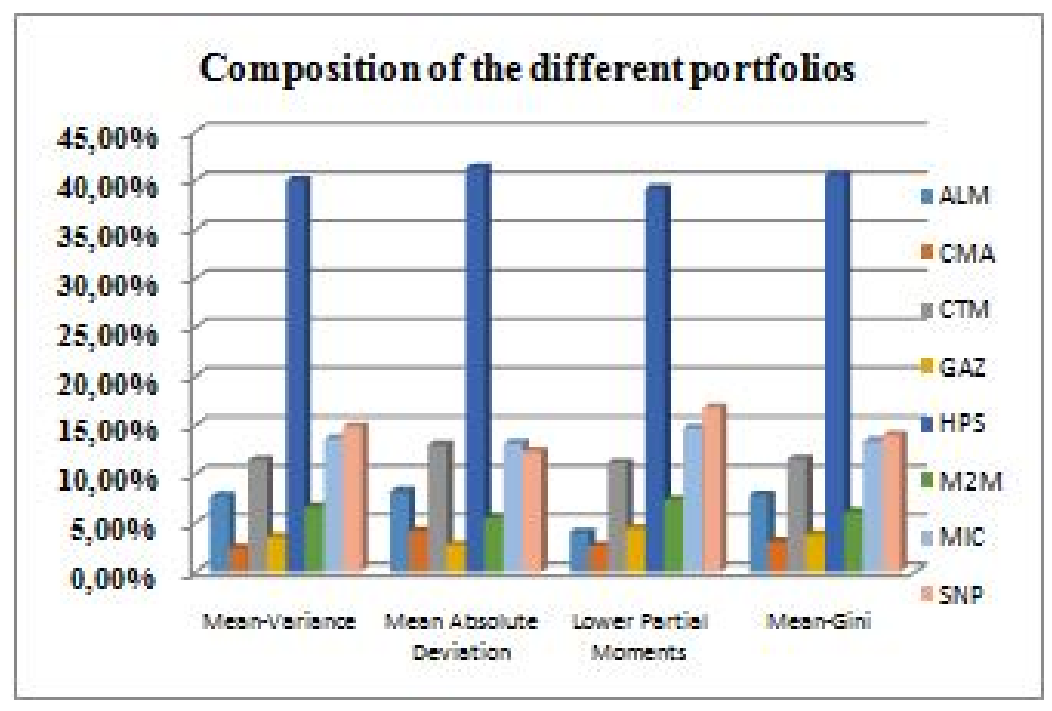

Figure 5: Composition of the different portfolios

HPS is in first place with 39.94, followed by SNP with 14.84, and CMA in last place with 2.40 , while the other shares are not part of the composition. Figure 5 provides a detailed overview of the composition of each portfolio. Then, the summary statistics of the optimal portfolios obtained by the resolution of the optimisation programmes are presented in the table 3 .

To compare the four stages over the crisis period, i.e. from the appearance of the first case of COVID-19 in Morocco Financial Market until now, we will use the Sharpe ration adjusted by each risk measure (Variance, Absolute Deviation (MAD), Lower Partial Moments (LPM) and Gini Coefficient). The results are presented in Table 4. These results show that the Mean-Lower Partial Moments (MLPM) strategy is the most efficient during this period of crisis compared to other strategies at the time. As shown in Figure 6 and 7, the Mean-Lower Partial Moments (MLPM) model is the

\section{Conclusion}

In this paper, we have assessed the contribution of the theoretical approach of Mean-Variance (MV), Mean-Absolute Deviation (MAD), one that represents the maximum performance of the Sharpe ratio adjusted by the different risk measures used. Whereas the two models Mean-Gini (MG) and Mean-Absolute Deviation (MAD) are in second position. Finally, the Mean-Variance (MV) model occupies the last position. In general, a higher Treynor Ratio indicates superior performance, and vice versa. In our case and based on the table 4 data, the Mean-Absolute Deviation (MAD) model is the best performing model, followed by Mean-Variance (MV) model which slightly outperforms the other two models: Mean-Lower Partial Moments (MLPM) and Mean-Gini (MG). The results for the Jensen Alpha show that the Lower Mean Partial Moment Model (MLPM) is the one that represents the maximum performance of the Jensen Alpha. Followed by the Mean-Absolute Deviation Model (MAD). While the Mean-Gini model (MG) takes third place. Finally, the Mean-Variance (MV) model occupies the last position.

Mean-Lower Partial Moments (MLPM) and Mean-Gini (MG) to the resolution of portfolio management problems in extreme periods within the Casablanca financial center . Empirical application on a

Table 3: Descriptive statistics of portfolio

\begin{tabular}{|c|c|c|c|c|}
\hline & $\begin{array}{c}\text { Mean- } \\
\text { Variance }\end{array}$ & $\begin{array}{c}\text { Mean-Abslute } \\
\text { Deviation }\end{array}$ & $\begin{array}{c}\text { Mean- } \\
\text { Semivariance }\end{array}$ & $\begin{array}{c}\text { Mean- } \\
\text { Gini }\end{array}$ \\
\hline Mean & -0.00011 & -0.00011 & -0.00010 & -0.00013 \\
\hline Median & 0.00141 & 0.00175 & 0.001757 & 0.00164 \\
\hline Maximum & 0.02676 & 0.02656 & 0.02712 & 0.02665 \\
\hline Minimum & -0.04877 & -0.04763 & -0.04697 & -0.04720 \\
\hline Std. Dev. & 0.01182 & 0.011768 & 0.01216 & 0.01181 \\
\hline Skewness & -0.99321 & -0.98486 & -0.92523 & -0.94871 \\
\hline Kurtosis & 5.18704 & 4.94169 & 4.41719 & 4.76167 \\
\hline J-Bera & 44.7365 & 39.2064 & 27.8424 & 34.3566 \\
\hline Probability & 0.00 & 0.00 & 0.00 & 0.00 \\
\hline MAD & $0.898 \%$ & $0.888 \%$ & $0.936 \%$ & $0.890 \%$ \\
\hline Semivariance & $0.949 \%$ & $0.957 \%$ & $0.970 \%$ & $0.951 \%$ \\
\hline Gini & $0.7406 \%$ & $0.7416 \%$ & $0.7416 \%$ & $0.7402 \%$ \\
\hline
\end{tabular}




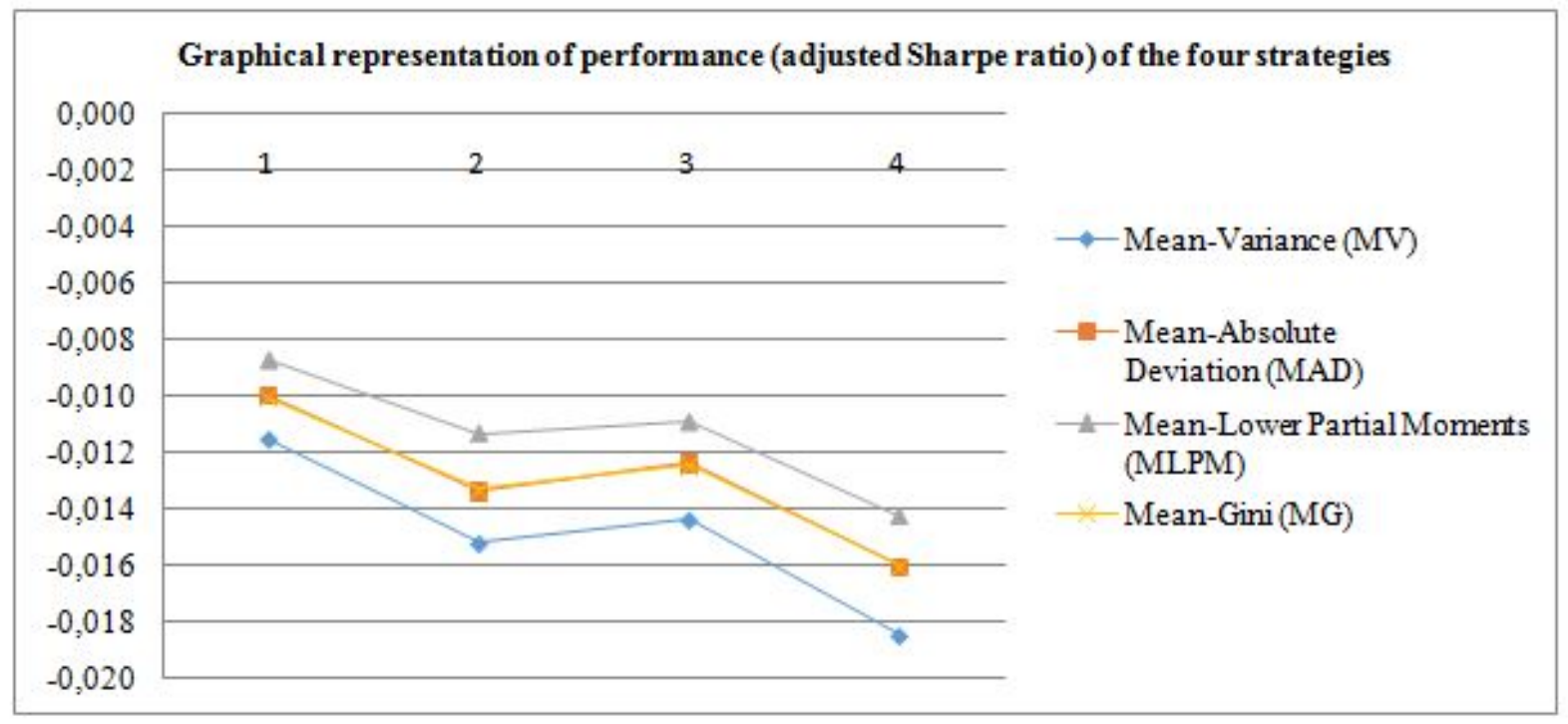

Figure 6: Graphical representation of performance (adjusted Sharpe ratio) of the four strategies.

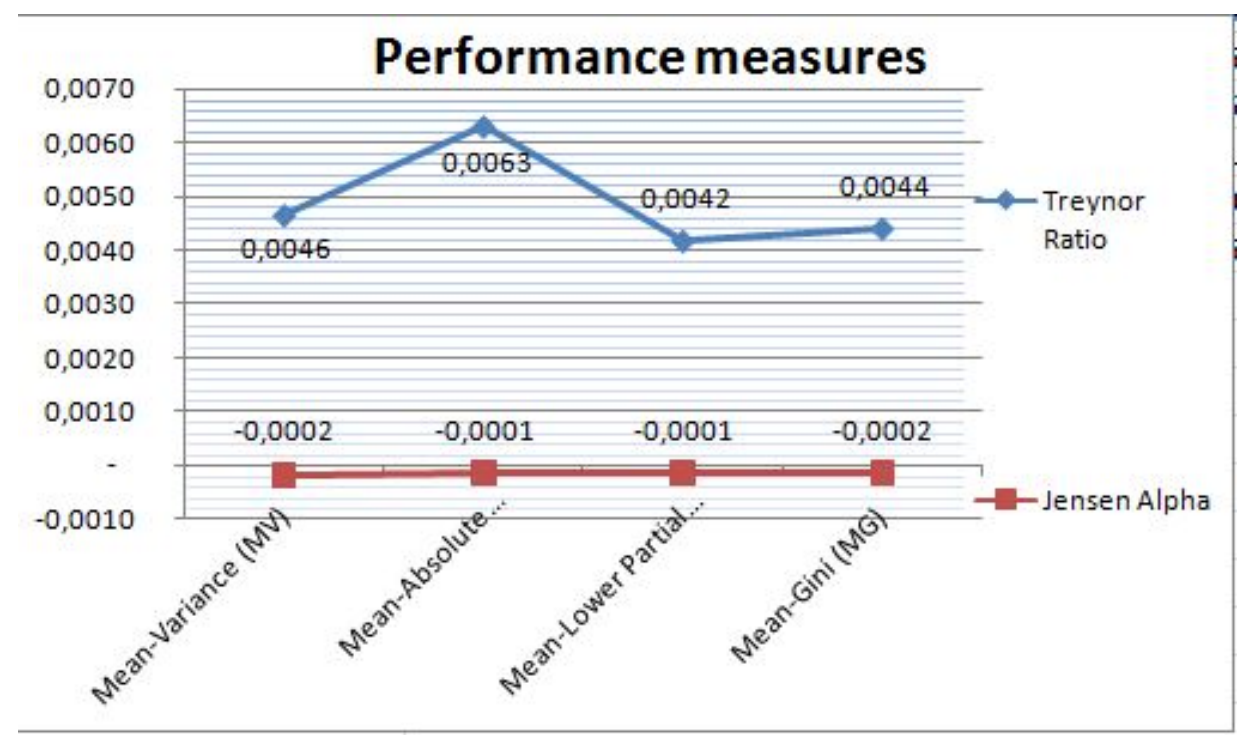

Figure 7: Graphical representation of performance (Treynor Ratio \& Jensen Alpha) of the four strategies.

sample of stocks belonging to the MADEX index allowed the selection of four performing portfolios with a better risk/return ratio over the period before COVID-19. The main results show the superiority of the Mean-Lower Partial Moments (MLPM) model over other models based on the results of the adjusted Sharpe ratio. This comparison has been made on the period of the onset and amplification of the COVID-19 pandemic in Morocco. Also note the inferiority of

Table 4: Performance measures (Sharpe ratio,Treynor Ratio and Jensen Alpha) adjusted by each risk measure (Variance, Absolute Deviation (MAD), Lower Partial Moments (LPM) and Gini Coefficient)

\begin{tabular}{|c|c|c|c|c|c|}
\hline \multicolumn{2}{|c|}{ performance measures } & $\begin{array}{c}\text { Mean- } \\
\text { Variance (MV) }\end{array}$ & $\begin{array}{c}\text { Mean-Absolute } \\
\text { Deviation (MAD) }\end{array}$ & $\begin{array}{c}\text { Mean- } \\
\text { Semivariance }\end{array}$ & $\begin{array}{c}\text { Mean- } \\
\text { Gini (MG) }\end{array}$ \\
\hline \multirow{4}{*}{ Sharpe ratio adjusted } & \multirow{4}{*}{$\begin{array}{l}\text { Return/Standard deviation } \\
\text { Return/Absolute Deviation } \\
\text { Return/Lower Partial Moments } \\
\text { Return/Gini }\end{array}$} & -0.0116140 & $-0,0100686$ & $-0,0087240$ & $-0,0100996$ \\
\hline & & -0.0152826 & -0.0134055 & -0.0113376 & -0.0133471 \\
\hline & & -0.0144509 & -0.0124426 & -0.0109366 & -0.0124972 \\
\hline & & -0.0185225 & -0.0160531 & -0.0143108 & -0.0160553 \\
\hline \multicolumn{2}{|c|}{ Treynor Ratio } & 0.0046469 & 0.0063047 & 0.0041626 & 0.0043972 \\
\hline \multicolumn{2}{|c|}{ Jensen Alpha } & -0.0001810 & -0.0001471 & -0.0001440 & -0.0001590 \\
\hline
\end{tabular}


the mean-variance (MV) model in terms of performance measured by the adjusted Sharpe ratio since the different series of returns composing our portfolios are volatile, leptokurtic and asymmetric. They lead to a rejection of the Jarque-Bera normality test. As a result, the distribution of daily returns of Moroccan equities deviates from the normal distribution. Similarly, the results for the Jensen Alpha show that theMean-Lower Partial Moments (MLPM) is the model that represents maximum performance, followed by the Mean-Absolute Deviation (MAD) and the Mean-Gini Model (MG) in third place. Finally, the Mean-Variance (MV) model comes in last place. On the other hand, the Mean-Absolute Deviation (MAD)) model is the best performing, followed by the mean variance (MV) model which slightly outperforms the other two models: the Mean-Lower Partial Moments (MLPM) and the mean Gini (MG) based on the treynor ratio results. The results for the Jensen Alpha show that the Lower Mean Partial Moment Model (MLPM) is the model that represents the maximum performance of the Jensen Alpha. This is followed by the Mean-Absolute Deviation (MAD). While the Mean-Gini Model (MG) is in third place. Finally, the Mean-Variance (MV) model occupies the last position.

Through these results, we conclude that the best model available to investors in the Moroccan financial market is the Mean-Lower Partial Moments model (MLPM) since it is the most appropriate model for our financial market and its characteristics.For that and despite the use of the Mean-Variance model in the optimization and management of portfolios by the majority of managers, we underline the inadequacy of this model to the reality of the Moroccan financial center. Indeed, this model is built on the assumption of normality of returns. However, the reality of the financial markets is far from approaching normal distribution law, as several works have pointed out (Agouram and Lakhnati [41].

Conflict of Interest The authors declare no conflict of interest.

Acknowledgment We would like to thank our professor, Lakhnati Ghizlane of the National School of Applied Sciences (ENSA), Ibn Zohr University, Agadir who has helped us a lot in this research.

\section{References}

[1] H. Markowitz, "The Utility of Wealth," Journal of Political Economy, 1952, doi:10.1086/257177.

[2] H. Markowitz, "Portfolio analysis," Journal of Finance, 8, 77-91, 1952.

[3] H. M. Markowitz, "Portfolio Selection, Cowles Foundation Monograph 16," New York, New York: JohnWiley and Sons, 1959MarkowitzPortfolio Selection: Cowles Foundation Monograph, 161959, 1959.

[4] J. Tobin, "Estimation of Relationships for Limited Dependent Variables," Econometrica, 1958, doi:10.2307/1907382.

[5] W. F. Sharpe, "Capital Asset Prices: A Theory of Market Equilibrium under Conditions of Risk," The Journal of Finance, 1964, doi:10.2307/2977928.

[6] J. Lintner, "SECURITY PRICES, RISK, AND MAXIMAL GAINS FROM DIVERSIFICATION," The Journal of Finance, 1965, doi:10.1111/j.1540-6261 1965.tb02930.x.

[7] J. Lintner, "The Valuation of Risk Assets and the Selection of Risky Investments in Stock Portfolios and Capital Budgets," The Review of Economics and Statistics, 1965, doi:10.2307/1924119.
[8] J. Mossin, "Equilibrium in a Capital Asset Market," Econometrica, 1966, doi:10.2307/1910098.

[9] V. S. Bawa, "Optimal rules for ordering uncertain prospects," Journal of Financial Economics, 2(1), 95-121, 1975.

[10] V. S. Bawa, E. B. Lindenberg, "Capital market equilibrium in a mean-lower partial moment framework," Journal of Financial Economics, 1977, doi: 10.1016/0304-405X(77)90017-4.

[11] P. C. Fishburn, "Condorcet Social Choice Functions," SIAM Journal on Applied Mathematics, 1977, doi:10.1137/0133030.

[12] W. V. Harlow, R. K. S. Rao, "Asset Pricing in a Generalized Mean-Lower Partial Moment Framework: Theory and Evidence," The Journal of Financial and Quantitative Analysis, 1989, doi:10.2307/2330813.

[13] J. P. Morgan, Reuters Ltd, RiskMetrics - Technical Document, 1996.

[14] P. Jorion, "Risk management lessons from long-term capital management," European Financial Management, 2000, doi:10.1111/1468-036X.00125.

[15] M. Grebeck, S. Rachev, "Stochastic programming methods in asset-liability management," Investment Management and Financial Innovations, 2005.

[16] J. L. Treynor, "Market Value, Time, and Risk (revised manuscript)," Unpublished manuscript dated 8/8/61, 1961, doi:10.2139/ssrn.2600356.

[17] J. L. Treynor, "Author : Jack L. Treynor Fall , 1962 (Revised 12/28 / 02 , with minor edits by Craig William French ) TOWARD A THEORY OF MARKET VALUE OF RISKY ASSETS,” 1(2), 15-22, 1962.

[18] S. A. Ross, "The arbitrage theory of capital asset pricing," Journal of Economic Theory, 1976, doi:10.1016/0022-0531(76)90046-6.

[19] E. Ballestero, "Mean-semivariance efficient frontier: A downside risk model for portfolio selection," Applied Mathematical Finance, 2005, doi:10.1080/ 1350486042000254015 .

[20] S. A. Bond, S. E. Satchell, "Statistical properties of the sample semi-variance," Applied Mathematical Finance, 2002, doi:10.1080/1350486022000015850.

[21] S. A. Bond, S. E. Satchell, "Asymmetry, loss aversion, and forecasting," Journal of Business, 2006, doi:10.1086/503649.

[22] J. Estrada, "Mean-semivariance behavior: Downside risk and capital asset pricing," International Review of Economics and Finance, 2007, doi: 10.1016/j.iref.2005.03.003.

[23] M. Unser, "Sampling - 50 years after Shannon," Proceedings of the IEEE, 2000, doi: $10.1109 / 5.843002$.

[24] H. Shalit, S. Yitzhaki, "Mean-Gini, Portfolio Theory, and the Pricing of Risky Assets," The Journal of Finance, 1984, doi:10.2307/2327737.

[25] S. Yitzhaki, "Stochastic Dominance, Mean Variance, and Gini's Mean Difference," American Economic Review, 1982, doi:10.2307/1808584.

[26] H. Shalit, S. Yitzhaki, "The mean-Gini efficient portfolio frontier," Journal of Financial Research, 2005, doi:10.1111/j.1475-6803.2005.00114.x.

[27] M. Cardin, B. Eisenberg, L. Tibiletti, "Mean-extended Gini portfolios personalized to the investor's profile," Journal of Modelling in Management, 2013, doi: $10.1108 / 17465661311311978$.

[28] H. Konno, H. Yamazaki, "Mean-Absolute Deviation Portfolio Optimization Model and Its Applications to Tokyo Stock Market," Management Science, 1991, doi:10.1287/mnsc.37.5.519.

[29] P. Artzner, F. Delbaen, J.-M. Eber, D. Heath, "Coherent measures of risk," Mathematical finance, 9(3), 203-228, 1999.

[30] D. N. Nawrocki, "Optimal algorithms and lower partial moment: Ex post results," Applied Economics, 1991, doi:10.1080/00036849100000021.

[31] D. N. Nawrocki, "The characteristics of portfolios selected by n-degree Lower Partial Moment," International Review of Financial Analysis, 1992, doi: $10.1016 / 1057-5219(92) 90004-\mathrm{N}$. 
[32] D. N. Nawrocki, "A Brief History of Downside Risk Measures," The Journal of Investing, 1999, doi:10.3905/joi.1999.319365.

[33] W. Y. Lee, R. K. S. Rao, "Mean Lower Partial Moment Valuation and Lognormally Distributed Returns," Management Science, 1988, doi:10.1287/mnsc.34. 4.446 .

[34] R. P. Bey, K. M. Howe, "Gini's Mean Difference and Portfolio Selection: An Empirical Evaluation," The Journal of Financial and Quantitative Analysis, 1984, doi:10.2307/2331094.

[35] J. Okunev, "MEAN GINI CAPITAL ASSET PRICING MODEL: SOME EMPIRICAL EVIDENCE," Accounting \& Finance, 1989, doi:10.1111/j. 1467-629X.1989.tb00155.x.

[36] J. Agouram, G. Lakhnati, "A Comparative Study of Mean-Variance and Mean Gini Portfolio Selection Using VaR and CVaR,” Journal of Financial Risk Management, 2015, doi:10.4236/jfrm.2015.42007.
[37] A. Jamal, L. Ghizlane, "Mean-Gini portfolio selection: Forecasting VaR using GARCH models in Moroccan financial market," Journal of Economics and International Finance, 2015, doi:10.5897/jeif2014.0630.

[38] J. Agouram, G. Lakhnati, "Mean-gini and mean-extended gini portfolio selection: An empirical analysis," Risk Governance and Control: Financial Markets and Institutions, 2016, doi:10.22495/rcgv6i3c1art7.

[39] C. S. Cheung, C. C. Kwan, P. C. Yip, "The hedging effectiveness of options and futures: A Mean-Gini approach,' Journal of Futures Markets, 10(1), 61-73, 1990.

[40] M. Berkhouch, G. Lakhnati, M. B. Righi, "Extended Gini-type measures of risk and variability," Applied Mathematical Finance, 25(3), 295-314, 2018.

[41] J. Agouram, J. Anoualigh, G. Lakhnati, "Capital Asset Pricing Model (CAPM) Study in Mean-Gini Model," International Journal of Applied Economics, Finance and Accounting, 6(1), 57-63, 2020. 